\title{
Investigation of the corrosiveness of moisture condensation conditions at gas production facilities in the presence of $\mathrm{CO}_{2}$
}

\author{
R.K. Vagapov, (iD* R.R. Kantyukov ${ }^{(i)}$ and D.N. Zapevalov ${ }^{(D)}$ \\ Gazprom VNIIGAZ LLC, 15 Proyektiruyemy proyezd 5537, bld. 1, Razvilka, Leninsky \\ municip., Moscow region, 142717, Russian Federation

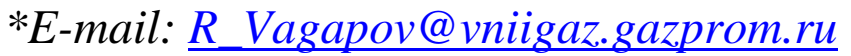

\begin{abstract}
Internal corrosion and corrosion protection measures represent a pressing challenge that hydrocarbon production facilities are faced with. The presence of $\mathrm{CO}_{2}$ and condensation water in the produced gas, as well as a number of other factors stimulate intensive propagation of carbon dioxide corrosion and local defects on steel. Corrosion tests were carried out under moisture condensation conditions, when a temperature gradient arises and the gas is rapidly cooled to determine the local corrosion limit rates. Tests studied the influence of various factors on corrosion processes under moisture condensation conditions in the presence of $\mathrm{CO}_{2}$ : humidity and acidity of the environment, alcohol footprint, temperature, steel grade and the weld availability. The temperature gradient that occurs between the medium and the steel surface and leads to moisture condensation has a strong impact on intensification of the localized corrosion. The strong growth of local defects can be caused by the presence of $\mathrm{CH}_{3} \mathrm{COOH}$ in the medium, which acidifies the moisture film, facilitates corrosion, and dissolves the forming layers of corrosion products (iron carbonate) on the steel surface. Due to heterogeneity of the surface in the weld area, the growth of local defects here is more active during moisture condensation, as compare to parent pipe. The paper investigates corrosion impact factors under condensation of water and alcohol solutions present in media and used as a hydrate inhibitor in gas production. It is shown that gas humidity and alcohol concentration are decisive for the development of this type of corrosion under $\mathrm{CO}_{2}$ conditions. The rate of corrosion depends on the amount and composition of the liquid condensing on the metal surface. The rate of local carbon dioxide corrosion in such environments can reach several $\mathrm{mm} /$ year.
\end{abstract}

Received: July 11, 2021. Published: July 29, 2021

doi: $\underline{10.17675 / 2305-6894-2021-10-3-11}$

Keywords: carbon dioxide corrosion, water condensation, corrosion rate, local corrosion.

\section{Introduction}

During hydrocarbon production, increased attention is paid to the problems of ensuring safety and durability at infrastructure facilities made of steel $[1,2]$. One of the main problems is the risk of internal corrosion development due to the presence of hazardous $\mathrm{H}_{2} \mathrm{~S}$ and $\mathrm{CO}_{2}$ in the produced fluids accompanied by additional corrosive factors (presence of water, elevated temperatures, etc.). Many operating gas production facilities are characterized by 
increased amounts of $\mathrm{CO}_{2}[3,4]$. A high degree of corrosion defects localization is the main hazard of carbon dioxide corrosion (CDC) [5-7].

Gas production facilities that differ from oil fields by corrosive conditions demonstrate several main corrosion formation zones $[8,9]$ :

- the lower part of the pipe (when moisture accumulates or bottom-of-line corrosion $(\mathrm{BOL}))$;

- the top of the pipe (in case of moisture condensation or top-of-line corrosion (TOL));

- places of moisture accumulation (cracks, gaps, stagnant zones, level difference etc.).

Basically, corrosion in the aqueous phase (BOL corrosion) is the main focus of corrosion studies, including those performed at hydrocarbon production facilities $[10,11]$. TOL cases accompanied by formation of condensation water during gas production have been limitedly studied in relation to the Russian gas fields. Our analysis showed that TOL corrosion was mainly investigated in the works of the foreign authors [7, 12-14].

In this study, we focused on the TOL corrosion, which is specific for and occurs at gas production facilities. Corrosion factors for the TOL tests were selected for the operating conditions of the Russian gas fields.

TOL corrosion initiate and development conditions as follows: high moisture content of the produced formation gas, creation of thermobaric conditions for water separation from the gaseous medium and its condensation on the inner surface of the upper part of the pipe.

\section{Experimental}

Experiments described in [15] for the atmospheric moisture condensation conditions were taken as a basis, when planning and carrying out CDC tests in a gaseous environment. Glass desiccators with a volume of up to $8 \mathrm{dm}^{3}$ served as corrosion cells. Glass tubes were placed inside (for cooling) to let, a cooler (cold water) pass (to reduce the temperature to $10^{\circ} \mathrm{C}$ ). To create saturated water vapor a liquid (distilled water separately or together with alcohol) was placed in a desiccator. The inlet and outlet of the cooler and gaseous $\mathrm{CO}_{2}$ and/or $\mathrm{N}_{2}$ were installed in the test cell. Gases separately or their mixture after premixing at a certain ratio were fed through a tube to the bottom of the desiccator across a liquid layer to accelerate saturation with liquid vapor. Steel samples were placed on cooling tubes to form a moisture film by condensation. An air thermostat was used to carry out the tests at higher than ambient temperatures. Thus, CDC tests were carried out under moisture condensation conditions at normal $\left(20-25^{\circ} \mathrm{C}\right)$ and elevated $\left(50^{\circ} \mathrm{C}\right)$ temperatures [16].

Various carbon and low alloy steel samples (09Mn2Si, X65), and steel, which is applied in the production of pipe tubing (J55LT) were used in tests. The temperature difference between the air environment $\left(20-25^{\circ} \mathrm{C}\right)$ and the artificially cooled steel surface $\left(10^{\circ} \mathrm{C}\right)$ reached up to $10-15^{\circ} \mathrm{C}$.

The authors have carried out tests under moisture condensation conditions in the presence of $\mathrm{CO}_{2}$. After the tests, corrosion rate $(K)$ was registered and measured. The rate of general corrosion was determined by the weight loss of the sample $\left(K_{\text {gen. }}\right)$. 
Local corrosion was determined by the depth of corrosion damage:

- average $\left(K_{\text {loc.av. }}\right)$ - by averaging all local defects;

- maximum $\left(K_{\text {loc.max. }}\right)$ - for the deepest local defect.

\section{Results and Discussion}

Laboratory tests in the gas environment have been carried out earlier [17, 18], including those performed for $\mathrm{CO}_{2}$. But in the vapor phase above the aqueous (water-hydrocarbon) environment where the test samples were located, due to the absence of a moisture film, corrosion was low, especially for $\mathrm{CO}_{2}$ environments (even under periodic shaking and contacting with a liquid medium under laboratory conditions). The samples were predominantly in a dry atmosphere, and corrosion did not develop. The rate of general corrosion in the vapor phase above the liquid was low and did not exceed $0.1 \mathrm{~mm} /$ year:

- in autoclave tests $\left(P\left(\mathrm{CO}_{2}\right)=5-10 \mathrm{MPa}\right)$ it totaled $0.001-0.011 \mathrm{~mm} /$ year (without contact with the aqueous phase) [18];

- in autoclave tests $0.026 \mathrm{~mm} /$ year (without contact with the aqueous phase) and $0.065 \mathrm{~mm} /$ year (with periodic contact with the aqueous phase) [17].

Steel St20 test data show that the rate of the general corrosion of the samples located above the $\mathrm{CO}_{2}$ aqueous medium is $0.01 \mathrm{~mm} /$ year: no local defects [9]. In the absence of a direct contact with the aqueous phase, corrosion is low-significantly below $0.1 \mathrm{~mm} /$ year. Similar data were obtained in [19] for carbon steel in a $\mathrm{CO}_{2}$ atmosphere over an aqueous electrolyte, where the rate of general corrosion was not higher than $0.02 \mathrm{~mm} / \mathrm{year}$, even with periodic wetting of the samples by shaking the test cell.

It is known [14] that TOL corrosion in the presence of $\mathrm{CO}_{2}$ requires a large amount of condensation moisture. This refers exactly to a permanent moisture film that appears on the steel surface.

It is a TOL corrosion typical of the gas fields that highlights the difference in corrosion conditions between gas and oil facilities [6]. When wet raw gas comes from the well and is transported through a pipeline, water vapor from the gas phase condenses on the inner surface of the pipe due to the temperature gradient between the wet gas flow and the environment, which leads to TOL corrosion. Evaluation studies show that the Russian and foreign fields can experience moisture condensation even in the well, when gas rises from the formation the TOL corrosion $[6,9,20]$.

Globally, carbon and low-alloy steels are frequently used in the construction of pipelines, and do not contain sufficient amount of chromium that can increase corrosion resistance [21]. Such steels are not resistant to CDC and are subject to TOL corrosion, which leads to destruction of pipelines. It is reported in [22] that the TOL corrosion rate of X65 steel can reach up to $3 \mathrm{~mm} / \mathrm{year}$ and is accompanied by a significant localization of the corrosion destruction process.

As was confirmed in [23], the corrosion rate depends on the humidity conditions of the vapor environment. The presence of $\mathrm{MgCl}_{2}$ reduces the water vapor content above the 
solution, thereby lowering the relative humidity, which, in turn, reduces the amount of water condensation falling out, and can even prevent its precipitation. As an example, we considered the dependences for saturated and semi-saturated $\mathrm{MgCl}_{2}$ (Figure 1). To create conditions for difference levels of moisture formation, we took: distilled water $(100 \%$ relative humidity), a saturated solution of $\mathrm{MgCl}_{2}$ diluted 2 times with water ( $\sim 66 \%$ relative humidity), and a saturated solution of $\mathrm{MgCl}_{2}(\sim 33 \%$ relative humidity). At $100 \%$ relative humidity (line 1): cooling of saturated water vapor from the experiment temperature $\left(t_{\text {env }}\right)$ $23^{\circ} \mathrm{C}$ to the refrigerator temperature $\left(t_{\text {cold }}\right) 12^{\circ} \mathrm{C}$ (line $1^{\prime}$ ) provides of $\sim 10 \mathrm{~g} / \mathrm{m}^{3}$ in the water vapor content, which gives the amount of moisture condensate required for the volume of the desiccator and the area of the cold elements. With a similar temperature drop (line $2^{\prime}$ ) for a relative humidity of $66 \%$ (line 2, for semi-saturated $\mathrm{MgCl}_{2}$ ), moisture condensate does not form as the temperature decreases to about $16^{\circ} \mathrm{C}$, because the dew point $(100 \%$ relative humidity) is not reached. Further cooling gives an amount of condensate proportional to the difference in water vapor content above line 1 (a segment in the area exceeding $100 \%$ relative humidity), i.e. approximately proportional to the drop in water vapor content by $3 \mathrm{~g} / \mathrm{m}^{3}$. For saturated $\mathrm{MgCl}_{2}$ (line 3), 33\% relative humidity, such temperature change (line $3^{\prime}$ ) is not capable to bring the system into the condensation range (the system does not reach $100 \%$ relative humidity) given the conditions of our experiment.

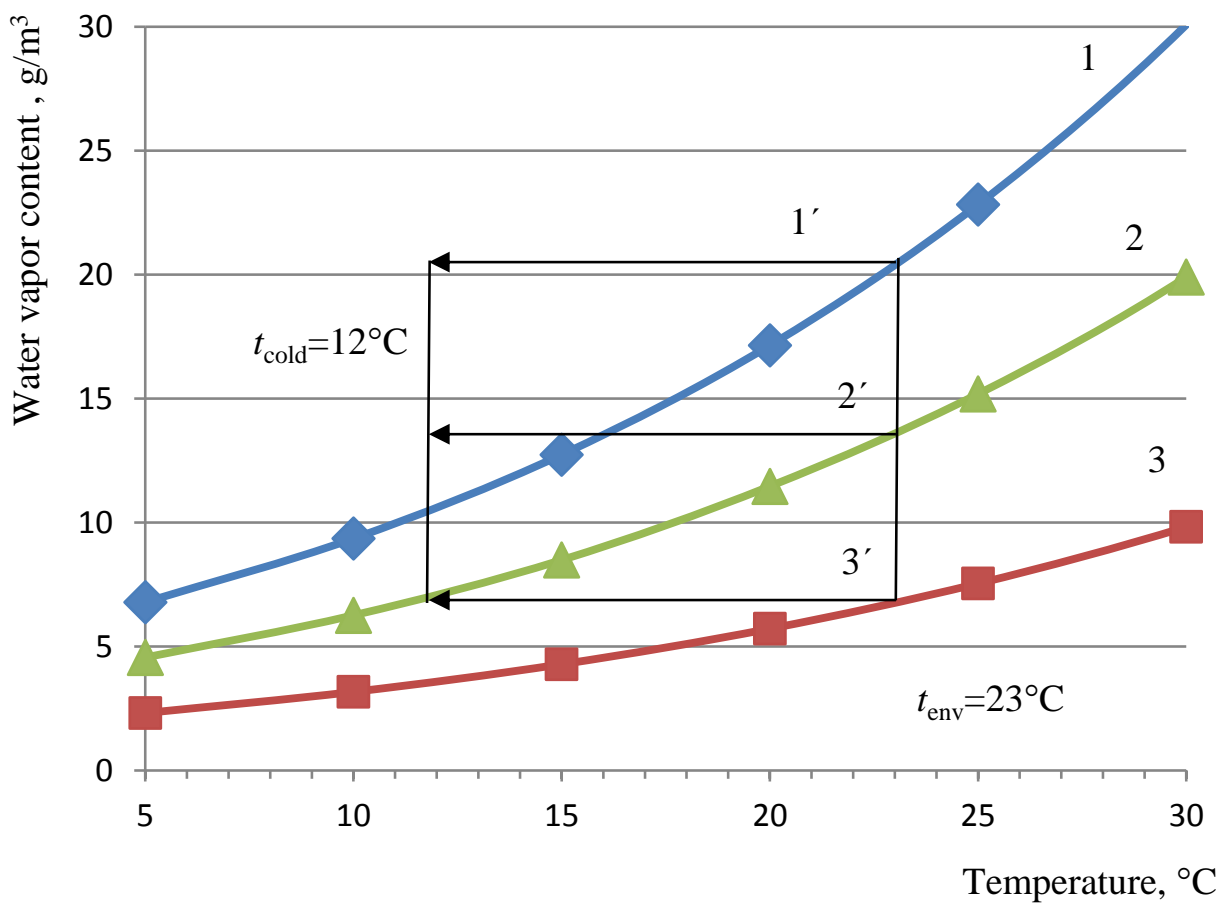

Figure 1. The water vapor content above: 1 - distilled water (100\% relative humidity), 2 - saturated $\mathrm{MgCl}_{2}$ solution diluted 2 times with water ( $\sim 66 \%$ relative humidity), and 3 saturated $\mathrm{MgCl}_{2}$ solution ( $\sim 33 \%$ relative humidity) according to [23]. 
Tables 1 and 2 show the results of evaluating the corrosion rate depending on the humidity conditions of the vapor environment. It can be seen that $33 \%$ humidity (saturated with $\mathrm{MgCl}_{2}$ ) with no moisture condensation occurred during the temperature drop, provides a low general corrosion rate $(0.0012 \mathrm{~mm} /$ year $)$, and no local corrosion. This is confirmed by the external view of samples after testing (Table 2): corrosion products are not formed, the surface of the steel sample remains unchanged. However, if there is a possibility of a slight difference in the content of water vapor $\left(3 \mathrm{~g} / \mathrm{m}^{3}\right)$ under $66 \%$ humidity (semi-saturated $\mathrm{MgCl}_{2}$ ) the steel surface changes its appearance upon reaction with corrosive reagents (water and $\mathrm{CO}_{2}$ ). But the amount of moisture is insignificant, and there is also no development of dangerous local damages: the general corrosion rate $(0.0070 \mathrm{~mm} /$ year $)$ remains at a low level (Table 1).

Table 1. St20 steel corrosion rate after testing under moisture condensation in the presence of $\mathrm{CO}_{2}$ according to $[23]$.

\begin{tabular}{cccc}
\hline \multirow{2}{*}{$\begin{array}{c}\text { Relative conditions } \\
\text { humidity, \% }\end{array}$} & \multicolumn{3}{c}{ Corrosion rate, mm/year } \\
\cline { 2 - 4 } & $\boldsymbol{K}_{\text {gen. }}$ & $\boldsymbol{K}_{\text {loc.av. }}$ & $\boldsymbol{K}_{\text {loc.max. }}$ \\
\hline 100 & 0.014 & 0.400 & 0.6 \\
66 & 0.0070 & No corrosion & No corrosion \\
33 & 0.0012 & No corrosion & No corrosion \\
\hline
\end{tabular}

Table 2. External view of steel samples after testing under moisture condensation conditions and in the presence of $\mathrm{CO}_{2}$ according to [23].

\begin{tabular}{c|c|c|c|}
\hline $\begin{array}{c}\text { Relative } \\
\text { humidity, \% }\end{array}$ & Witn corrosion products & After removing of corrosion products \\
\hline 100 & & & \\
\hline
\end{tabular}

Localization of CDC corrosive processes occurs only at 100\% humidity. Multiple pitting defects are visible on the steel sample after removal of corrosion products (Table 2). Calculations show (Table 1) that at a sufficiently low general corrosion rate of 
$0.014 \mathrm{~mm} /$ year, the rates of local average and maximum corrosion reach 0.4 and $0.6 \mathrm{~mm} /$ year respectively.

A decrease in temperature and the associated change in the amount of moisture in the air also affects the formation and development of TOL corrosion [24-27].

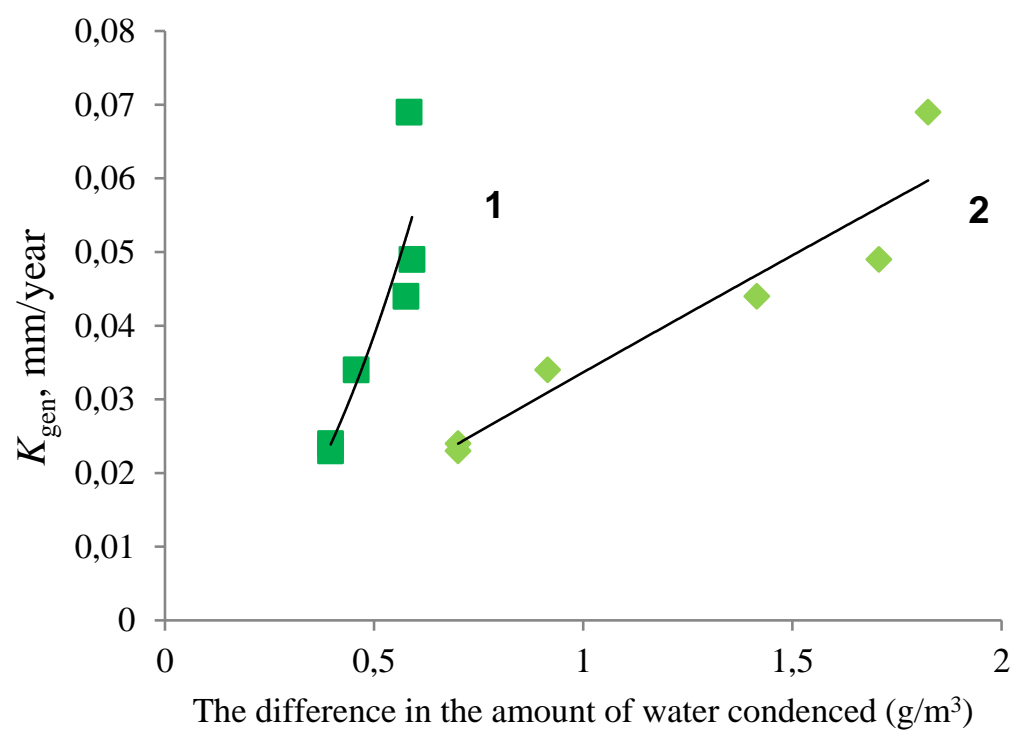

(A)

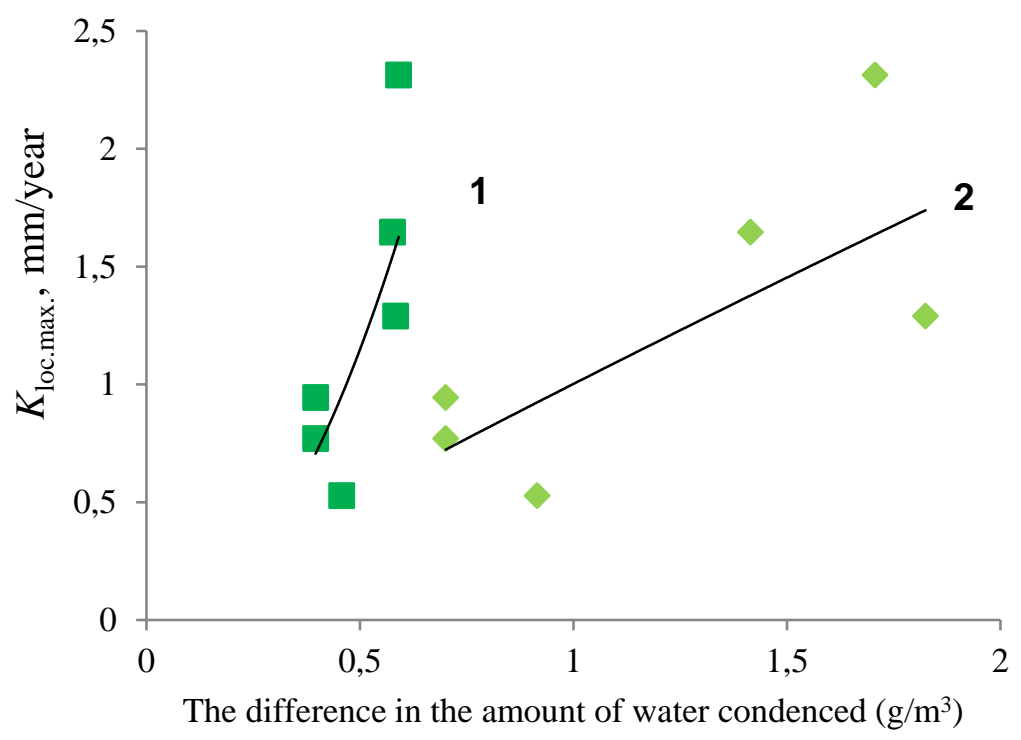

(B)

Figure 2. Dependence of the general (A) and maximum local (B) corrosion rates of carbon and low-alloy steels on the difference in the amount of water condensed on the steel surface relative to the test temperature (1) and to the temperature of the "cooler" (2) in the presence of $\mathrm{CO}_{2}$ and under moisture condensation conditions according to [28].

The results of TOL tests on different types of steel (09Mn2Si, J55LT) showed [16] that the rate of local corrosion $\left(K_{\text {loc.av. }}=0.42-1.43 \mathrm{~mm} /\right.$ year; $K_{\text {loc.max. }}=0.54-1.95 \mathrm{~mm} /$ year $)$ was 
higher at a greater temperature difference between the air environment and the steel sample surface, which may be associated with a large amount of moisture precipitation. General corrosion rate remains low (below $0.1 \mathrm{~mm} /$ year). Additional test data for different steels provided in [16] are shown in Figure 2. As can be seen, the rates of the general and maximum local corrosion in the tested carbon and low-alloy steels (St20, 09G2S, J55LT) depend on the amount of moisture condensed on the steel surface. The water content in the Figure 2 is given relative to the test temperature and to the temperature of the "cooler" (glass tubes through which cold water is transported), where steel samples are located and cooled.

Table 3. Corrosion rates under moisture condensation conditions and $\mathrm{CO}_{2}$ partial pressure $(0.1 \mathrm{MPa})$.

\begin{tabular}{|c|c|c|c|}
\hline $\begin{array}{l}\text { Steel type / Corrosion } \\
\text { environment / Conditions }\end{array}$ & $\begin{array}{c}K_{\text {gen., }} \\
\text { mm/year }\end{array}$ & $\begin{array}{l}K_{\text {loc.av. }} \\
\text { mm/year }\end{array}$ & View of steel samples after test \\
\hline Stainless steel $12 \mathrm{X} 18 \mathrm{H} 10 \mathrm{~T}$ & 0.0001 & $\begin{array}{l}\text { No local } \\
\text { corrosion }\end{array}$ & \\
\hline Carbon steels / water & 0.02 & 0.8 & \\
\hline $\begin{array}{l}\text { Carbon steels / water / } \\
\text { elevated temperature }\end{array}$ & 0.2 & 1.9 & \\
\hline $\begin{array}{c}\text { Carbon steels / water- alcohol } \\
\text { solution (WAS) }\end{array}$ & 0.05 & 0.8 & \\
\hline $\begin{array}{l}\text { Carbon steels / WAS / } \\
\text { elevated temperature }\end{array}$ & 0.09 & 1.7 & \\
\hline Carbon steels / water / weld & 0.08 & 1.6 & \\
\hline
\end{tabular}

The temperature can accelerate moisture condensation (Table 3 ). According to the results of X65 TOL tests carbon steel at $20-25$ and $50^{\circ} \mathrm{C}$, increase in the rate of moisture condensation caused by a larger temperature gradient (at a higher initial temperature of metal samples) is the main factor in the corrosion process: the local corrosion rate increases from 0.8 to $1.9 \mathrm{~mm} /$ year (Table 3) [16]. As the temperature rises, the determining factor in the 
acceleration of TOL corrosion is the increase in the amount of condensation moisture, although an additional influence of the temperature factor is also possible [29].

TOL corrosion at foreign gas fields with high $\mathrm{CO}_{2}$ content [30-32] causes the development of local defects at a rate of $0.95-1.9 \mathrm{~mm} /$ year. The analysis highlights that the rates of the local TOL corrosion (up to several $\mathrm{mm} / \mathrm{year}$ ) obtained during simulation tests of carbon and low-alloy steels (Table 3) are similar to pitting corrosion recorded during the operation of gas production facilities.

TOL corrosion tests and corrosion resistance analysis [33] underscored that local defects can develop on carbon and low-alloy steels in the operating conditions of production facilities in the presence of $\mathrm{CO}_{2}$ and moisture condensation. Alloys with a high chromium content for example stainless steel can be more resistant in such harsh conditions. According to the test data, stainless steel $12 \mathrm{X} 18 \mathrm{H} 10 \mathrm{~T}(18 \% \mathrm{Cr})$ was resistant and did not change after the TOL corrosion tests (Table 3). Such corrosion-resistant steels can be effective and resistant to CDC due to the formation of protective chromate films on the steel [34].

A water-alcohol solution (WAS) was taken as the test liquid, because methanol is used as an inhibitor of hydrate formation at gas facilities [35, 36]. Transmitted WAS can have different concentrations depending on the alcohol content and the amount of water (condensation or reservoir) and can vary across the field infrastructure. 10\% water solution of isopropanol was used in test. Deep local damage is observed on steel 20: local corrosion rate is 0.8 and $1.7 \mathrm{~mm} /$ year at $20-25$ and $50^{\circ} \mathrm{C}$, respectively (Table 3). The general corrosion rate of the same steel samples remains low $(0.061 \mathrm{~mm} /$ year $)$. Figure 3 shows that temperature accelerates corrosion not only in water, but also in WAS.

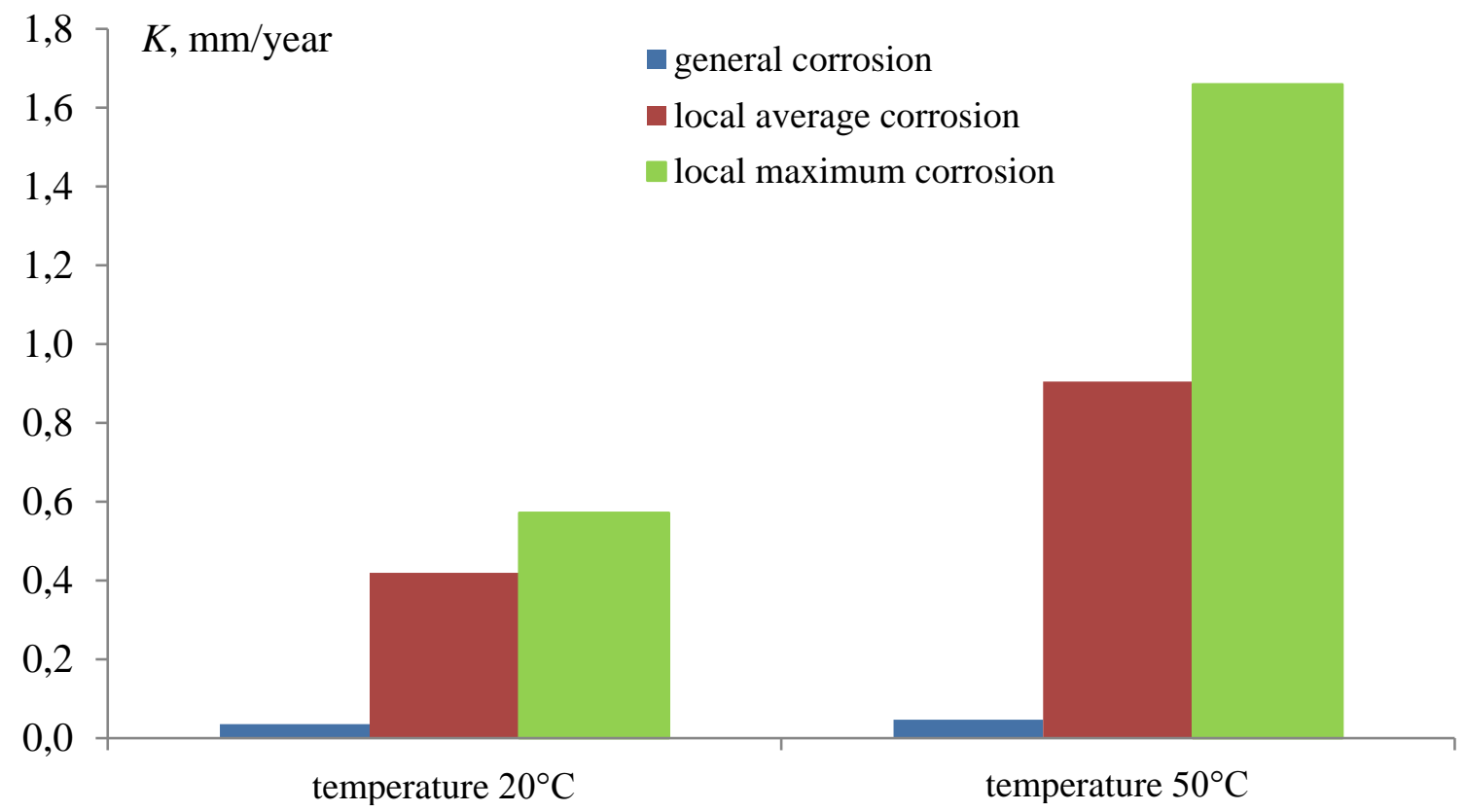

Figure 3. View of steel St20 samples after testing under moisture condensation conditions (water: isopropanol $=90: 10$ ) in the presence of $\mathrm{CO}_{2}$. 
The test results in WAS (10\% isopropanol) are identical to a purely aqueous solution: local defects are formed (Table 3). During processing of the produced gas, the concentration of alcohol in WAS can increase and after its regeneration can reach up to 85-90\%. Such technological transformations are accompanied by WAS heating/cooling and its condensation. Therefore, TOL corrosion tests were carried out for X65 carbon steel in the presence of $\mathrm{CO}_{2}$ in a range of different concentrations of WAS (Figure 4). It can be seen that TOL corrosion rate grows in the presence of $\mathrm{CO}_{2}$ upon condensation of WAS (up to $75 \%$ isopropanol). But starting from $75-80 \%$ concentration, isopropanol begins to suppress the $\mathrm{CDC}$ in the film of condensed liquid and there is a downward trend.

In contrast to water test conditions (BOL corrosion), when the addition of alcohol can directly (to some extent) reduce the destruction of steel (due to the replacement of corrosive water by alcohol) under liquid condensation conditions (TOL corrosion), the composition of the medium condensed on a steel surface plays a decisive role. It may differ in the concentration of alcohol from the original evaporated WAS. In the same way, the composition of the condensation layer (with an increase in the alcohol content) will also affect the CDC.

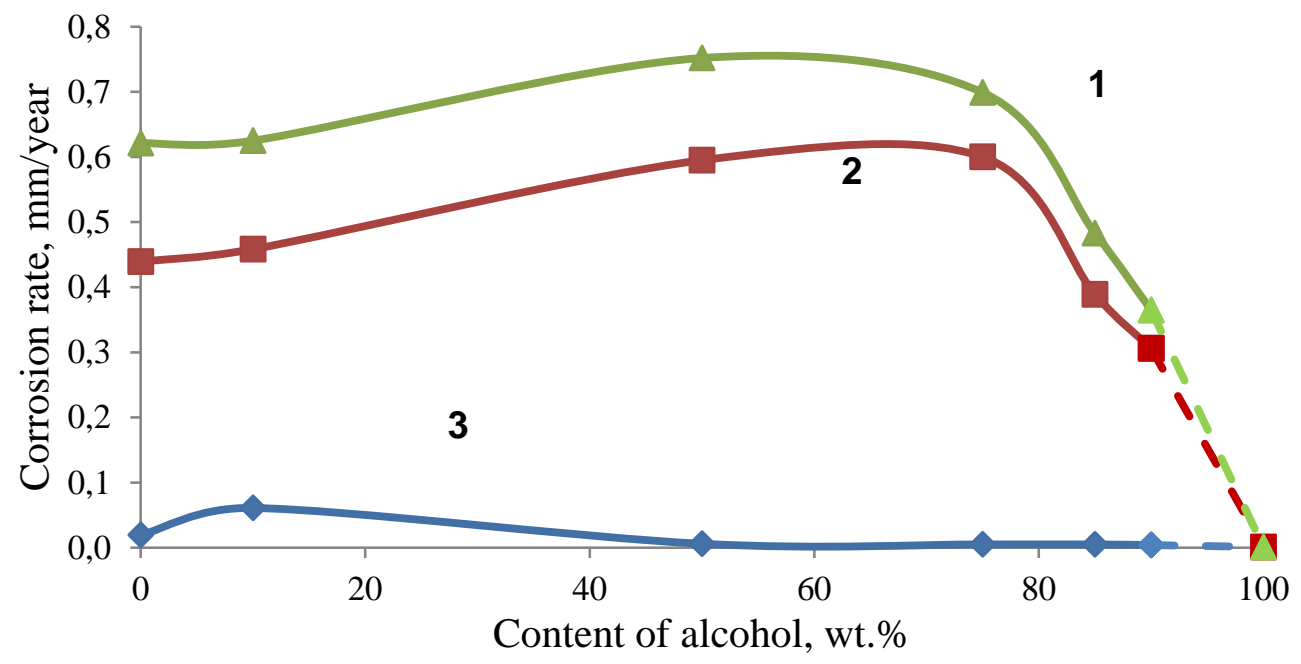

Figure 4. Dependence of steel 20 corrosion rates on the concentration (wt.\%) of the evaporated WAS: $1-K_{\text {loc.max.; }} 2-K_{\text {loc.av.; }} 3-K_{\text {gen. }}$ [37].

This tendency is observed for WAS in a wide range of alcohol concentrations in water (in an evaporated liquid). For TOL corrosion, the composition of the liquid condensed on the steel surface is important, as corrosion processes take place exactly there. When the concentration of alcohol in the WAS condensed on steel reaches high values, the local corrosion rate begins to decrease.

Our TOL tests have shown that X65 steel, like other steels (Steel 20, 09Mn2Si, J55LT) is not resistant to local CDC (Table 3). Pipeline weld seams can be exposed to greater corrosion destruction and instability to $\mathrm{CDC}$ [8]. These areas affected by thermal impact will 
have heterogeneity with respect to the parent pipe surface, and therefore may be subject to increased corrosion hazard in the case of CDC.
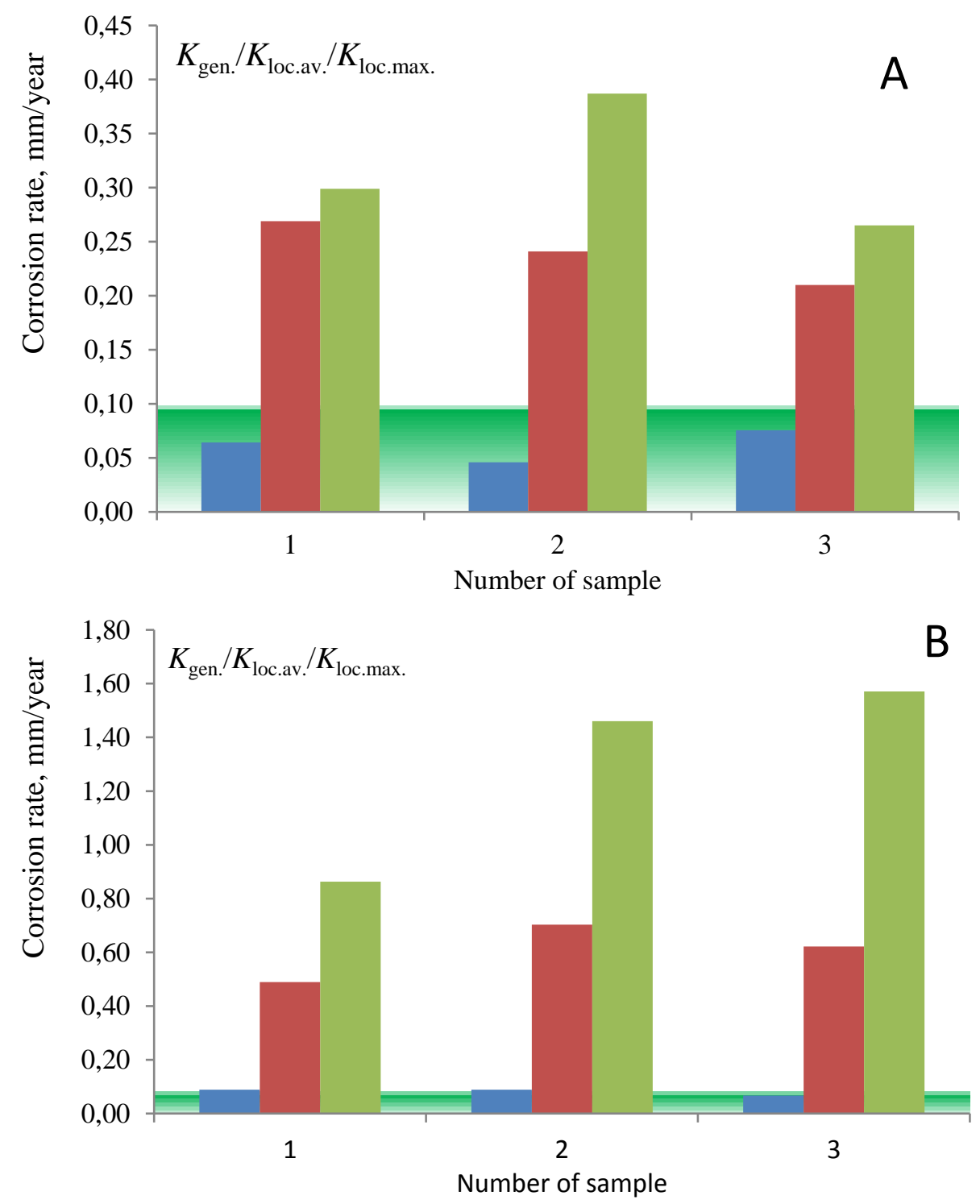

Figure 5. Comparison of steel corrosion rates: $K_{\text {gen. }} / K_{\text {loc.av. }} / K_{\text {loc.max.: }} \mathrm{A}$ - parent pipe; B - weld seam [28].

An additional point is that the weld reinforcement can result in possible delay and accumulation of aqueous liquid before and after it. The results of TOL tests of X65 steel samples cut from the parent metal ("pipe body", without a weld seam) and with a welded seam (in the middle of the specimen) are showed in Figure 5 and in Table 4. According to our research, the local corrosion rate measured by the depth of corrosion damage totals $0.265-0.387 \mathrm{~mm} /$ year during condensation and the creation of a thin film of moisture in the presence of $\mathrm{CO}_{2}$ on the parent pipe samples. Under the same conditions, the growth rate of local damage in weld seam can reach up to $0.867-1.571 \mathrm{~mm} /$ year (Figure 5). In TOL 
conditions, the CDC develops on a weld seam 3-4 times faster than on a parent pipe sample. Table 4 shows that after the tests, the appearance of the weld seam specimen differs in color, with local defects mainly in the welded zone.

Steel samples were tested under moisture condensation conditions to evaluate the impact of different $\mathrm{CO}_{2}$ content (partial pressure): for $\mathrm{CO}_{2}(0,25,50,75$ and 100\%), the partial pressure totaled $0 ; 0.025 ; 0.05 ; 0.075$ and $0.1 \mathrm{MPa} \mathrm{CO}_{2}$ respectively. For such condensation conditions, corrosion defects were localized on the surface of metal samples as multiple pits (Table 5).

Table 4. General view of parent pipe and weld seam specimens after removal of corrosion products [28].

\begin{tabular}{|c|c|c|}
\hline \multirow{2}{*}{$\begin{array}{c}\text { Number of the } \\
\text { sample }\end{array}$} & \multicolumn{2}{|c|}{ General view } \\
\hline & Parent pipe & Weld seam \\
\hline 1 & & \\
\hline 2 & & \\
\hline 3 & & \\
\hline
\end{tabular}

Figure 6 provides summary 09Mn2Si pipe steel test data for moisture condensation in the presence of $\mathrm{CO}_{2}$.

According to Figure $6 \mathrm{~A}$, the $K_{\text {gen }}$ is below $0.03 \mathrm{~mm} /$ year at room temperature under experimental conditions $\left(20-25^{\circ} \mathrm{C}\right)$ for steels tested at all $\mathrm{CO}_{2}$ contents $(0-100 \%)$. But it increases 10 times, when the temperature drops to $15^{\circ} \mathrm{C}$ from a higher value $\left(50^{\circ} \mathrm{C}\right)$, and the amount of precipitated moisture increases compared to the initial values of $20-25^{\circ} \mathrm{C}$. General corrosion values exceed $0.1 \mathrm{~mm} /$ year with a larger temperature gradient.

A similar tendency is observed with a local corrosion, which grows 2-3 times with a temperature increase (from $20-25^{\circ} \mathrm{C}$ to $50^{\circ} \mathrm{C}$ ). Figure $6 \mathrm{~B}$ provides data on the maximum local corrosion calculated by the deepest pitting. In the absence of $\mathrm{CO}_{2}$, local corrosion defects are not formed. With an increase in $\mathrm{CO}_{2}$ content (from 25 to $75 \%$ ), the rate of local corrosion also increases, which is significantly higher than $0.1 \mathrm{~mm} / \mathrm{ear}$, and according to the 
test results reaches $1.43 \mathrm{~mm} /$ year. Then it slightly decreases with a further increase to $100 \%$ $\mathrm{CO}_{2}$.
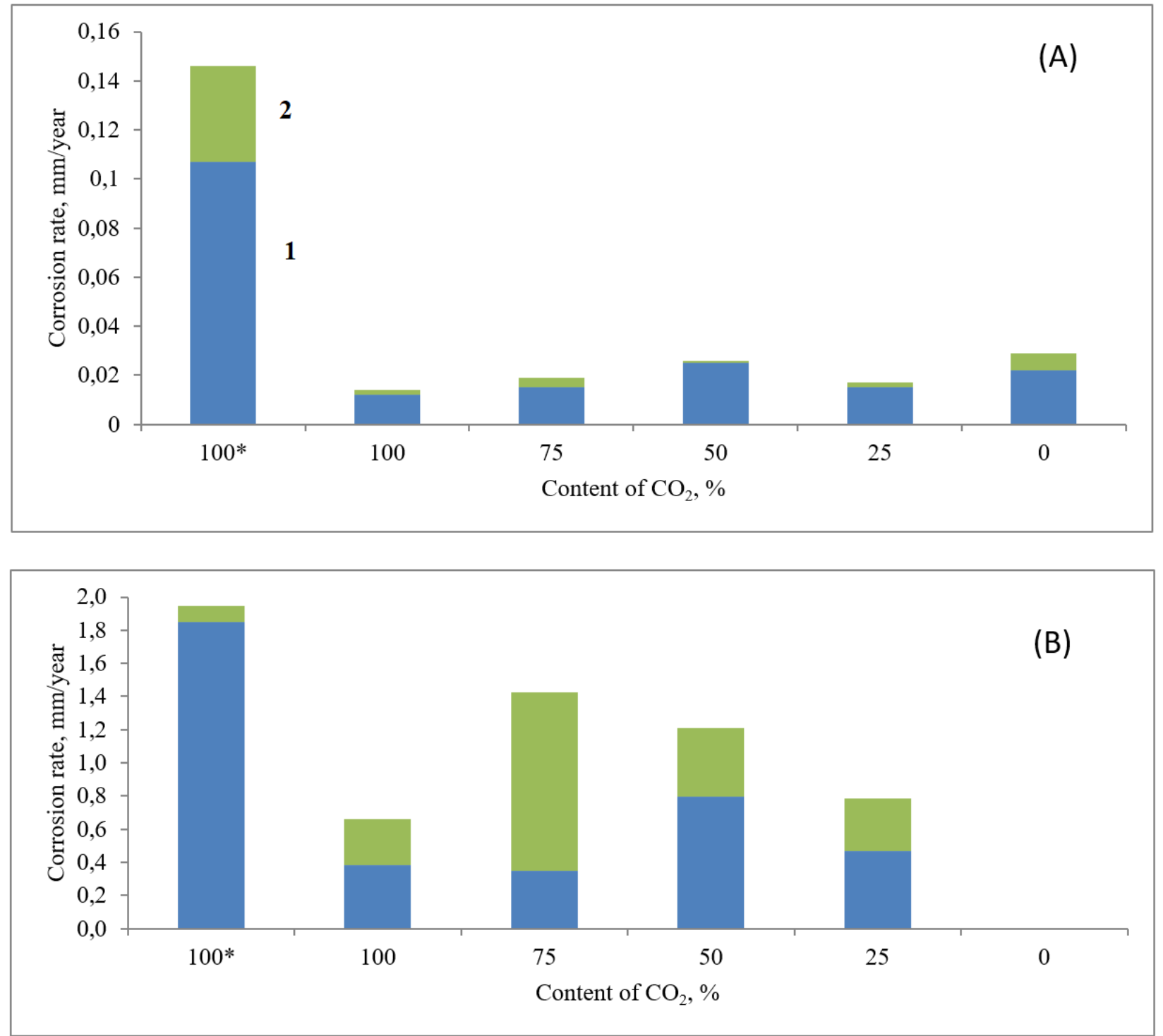

* test at elevated temperature $50^{\circ} \mathrm{C}$ corrosion.

Figure 6. The rate of corrosion measured on carbon steel samples in the presence of $\mathrm{CO}_{2}$ under water condensation conditions, temperature $20^{\circ} \mathrm{C}$ : A - general corrosion; B - local corrosion. 1 - average value; 2 - difference between maximum and average values.

Perhaps this is due to the formation of corrosion products (iron carbonate): at $100 \%$ $\mathrm{CO}_{2}$, the siderite, which forms more intensively and fills the pits on the steel surface at depth, prevents the deeper development of local defects. $\mathrm{FeCO}_{3}$ precipitate in pitting can create difficulties in the supply of corrosive agents deep into the defect [38]. The appearance of specimens with local defects after testing shown in Table 5 confirms that at 75 and $100 \%$ $\mathrm{CO}_{2}$ the number of defects is comparable, but the depth of the deepest ones is higher at $75 \%$ 
(Figure 6B). When analyzing this case, the following should be noted: the value " 1 " in Figure 6 means the average $K$, and " 2 " - the difference between the maximum and average $K$ values.

Table 5. Appearance of samples after tests with different $\mathrm{CO}_{2}$ content at room temperature $\left(20-25^{\circ} \mathrm{C}\right)$.

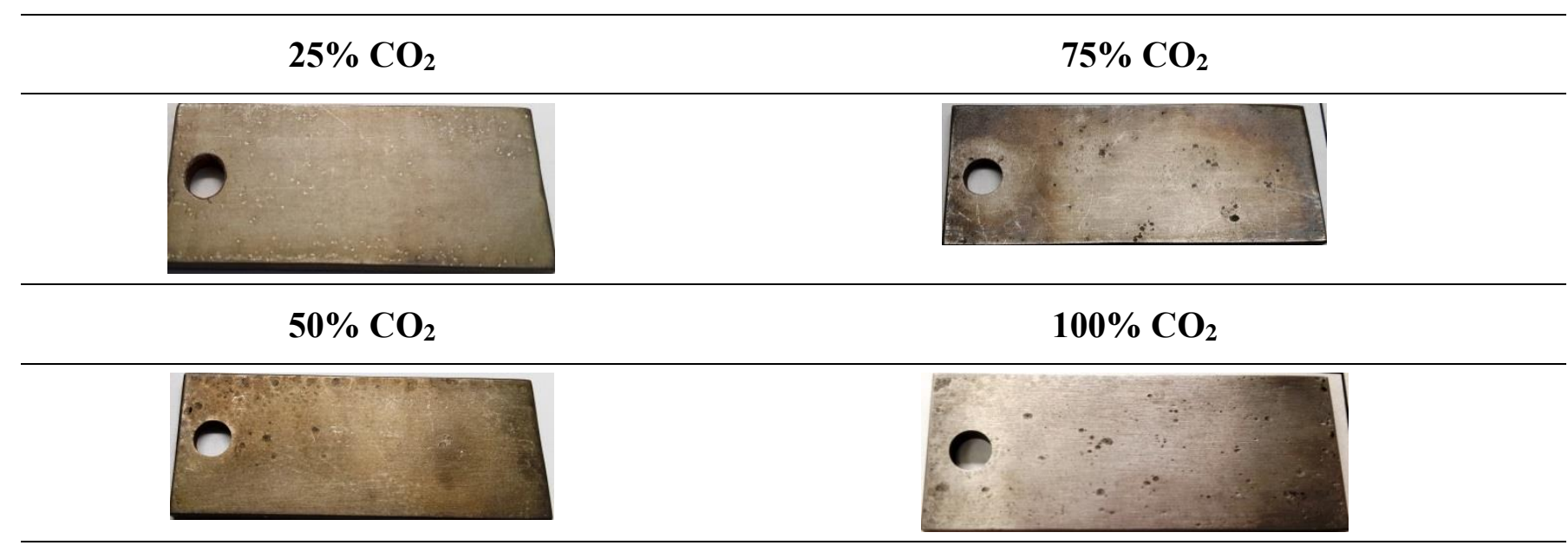

at elevated temperature $\left(50^{\circ} \mathrm{C}\right)$ and $100 \% \mathrm{CO}_{2}$

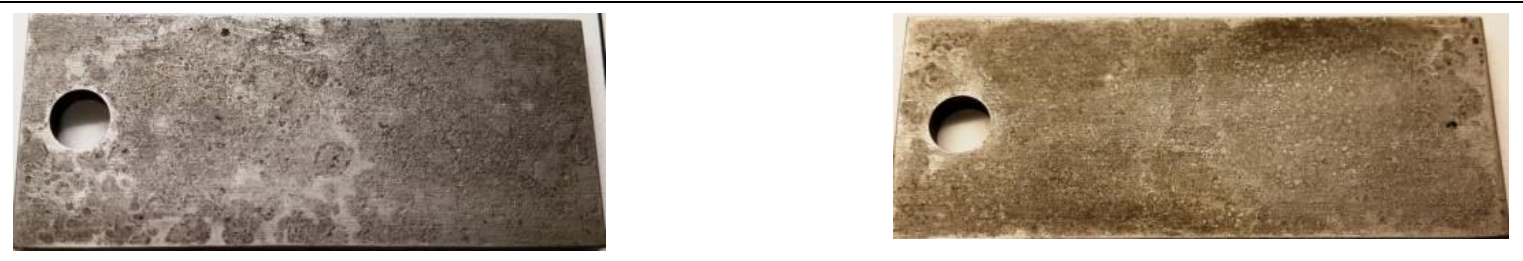

Produced hydrocarbons may contain carboxylic acids, for example, $\mathrm{CH}_{3} \mathrm{COOH}$, which, due to their volatility, especially at high temperatures, will make the TOL condensed aqueous medium more acidic and intensify steel corrosion $[39,40]$. TOL corrosion tests conducted under condensation of a liquid containing $\mathrm{CH}_{3} \mathrm{COOH}$ and in the presence of $\mathrm{CO}_{2}$ showed that there is an increase in the localization of defects on steel (Table 6). The general corrosion rate remains relatively low, while localized corrosion develops. The addition of $\mathrm{CH}_{3} \mathrm{COOH}$ to the evaporated liquid provides 2-3 times increase in local defects in comparison with a non-acidic aqueous solution. A similar increase in TOL corrosion under CDC conditions and the presence of $\mathrm{CH}_{3} \mathrm{COOH}$ was observed by foreign researchers $[41,42]$.

The resulting corrosion products (iron carbonates) can have a certain protective effect, which decreases under acidic conditions. The addition of $\mathrm{CH}_{3} \mathrm{COOH}$ shifts the $\mathrm{pH}$ factor in the condensed moisture film to more acidic values, at which the formed corrosion products dissolve [43-45]. 
Table 6. The general and local corrosion rates measured on the same carbon steel samples St 20 under moisture condensation conditions (distilled water) in the presence of $0.1 \mathrm{MPa} \mathrm{CO}_{2}$, temperature $20^{\circ} \mathrm{C} \mathrm{[8].}$

\begin{tabular}{|c|c|c|c|}
\hline $\begin{array}{l}\text { Concentration of } \\
\mathrm{CH}_{3} \mathrm{COOH}, \mathrm{mg} / \mathrm{L}\end{array}$ & $K_{\text {gen., }}, \mathbf{m m} /$ year & $\begin{array}{c}K_{\text {loc.av }} / K_{\text {loc.max., }}, \\
\text { mm/year }\end{array}$ & $\begin{array}{c}\text { View of steel samples } \\
\text { after tests }\end{array}$ \\
\hline 0 & 0.02 & $0.32 / 0.384$ & 15 \\
\hline 250 & 0.05 & $0.373 / 0.527$ & D \\
\hline 1000 & 0.05 & $0.81 / 1.015$ & \\
\hline
\end{tabular}

\section{Conclusions}

TOL corrosion tests showed that the majority of carbon and low-alloy steels (Steel 20, 09Mn2Si, X65, etc.) can be exposed to local corrosion in the operating conditions of gas production facilities in the presence of $\mathrm{CO}_{2}$ and moisture condensation. Alloys with a high chromium content are the most resistant in such a harsh environment. A larger temperature gradient of the medium and the steel surface leads to a greater condensation of moisture, and accordingly to an increase in local corrosion.

Tests indicate that initiation of TOL corrosion requires a high humidity level in the vapor environment sufficient for moisture condensation on the steel surface. The presence of $\mathrm{CH}_{3} \mathrm{COOH}$ in the medium leads to an increase in the rate of TOL corrosion and the depth of local defects.

Weld seams and heat-affected zone are heterogeneous with respect to the parent pipe surface, and are more exposed to TOL corrosion. Local defects are mainly located on the weld seam and in the heat-affected zone of the steel specimen.

In a water-alcohol environment, the alcohol content of the condensate water on steel plays an important role in TOL corrosion tests, rather than the evaporated liquid. When the concentration of alcohol in water is $75-80 \%$ and higher, corrosion can slow down, and CDC in the film of liquid condensed can be suppressed.

\section{References}

1. R.K. Vagapov, Increasing the corrosion resistance of oil production equipment and pipelines, Prot. Met., 2008, 44, no. 7, 667-672. doi: 10.1134/S0033173208070047 
2. Trends in Oil and Gas Corrosion Research and Technologies. Production and Transmission, Woodhead Publishing, Ed.: A.M. El-Sherik, 2017, 890 pp.

3. R.R. Kantyukov, D.N. Zapevalov and R.K. Vagapov, Hazard Assessment of the Internal Carbon Dioxide Corrosion of the Field Pipelines at the Gas and Gas Condensate Fields, Bezop. Tr. Prom-sti., 2021, no. 2, 56-62 (in Russian). doi: 10.24000/0409-2961-20212-56-62

4. D.N. Zapevalov and R.K. Vagapov, Analysis of regulatory requirements for the assessment of carbon dioxide corrosion at gas production facilities, Issues of Risk Analysis, 2021, 18, no. 2, 60-71 (in Russian). doi: 10.32686/1812-5220-2021-18-2-60-71

5. A.H. Alamri, Localized corrosion and mitigation approach of steel materials used in oil and gas pipelines - An overview, Eng. Failure Anal., 2020, 116, Article 104735. doi: 10.1016/j.engfailanal.2020.104735

6. D. Zapevalov and R. Vagapov, Possibilities and limitations of the organization of anticorrosion protection at gas production facilities, E3S Web Conf., 2021, 225, Article 03002. doi: $10.1051 / \mathrm{e} 3$ sconf $/ 202122503002$

7. M. Singer, Study of the Localized Nature of Top of the Line Corrosion in sweet environment, Corrosion, 2017, 73, no. 8, 1030-1055. doi: 10.5006/2222

8. R. Vagapov, Top-of-line corrosion in the presence of carbon dioxide for gas production facilities, E3S Web Conf., 2021, 225, Article 01002. doi: $\underline{10.1051 / \mathrm{e} 3 \mathrm{sconf} / 202122501002}$

9. D. Zapevalov and R. Vagapov, Aspects of protection against carbon dioxide corrosion of gas production facilities, E3S Web Conf., 2019, 121, Article 02013. doi: 10.1051/e3sconf/201912102013

10. B. Kermani and D. Harrop, Corrosion and Materials in Hydrocarbon Production: A Compendium of Operational and Engineering Aspects, John Wiley \& Sons Ltd, 2019, $344 \mathrm{pp}$.

11. S. Papavinasam, Corrosion Control in the Oil and Gas Industry, Gulf Professional Publishing, 2014, 992 pp.

12. D. Pugh, S. Asher, N. Berchane, J. Cai, W.J. Sisak, J.L. Pacheco, F.C. Ibrahim, E.J. Wright, A. Dhokte, V. Sunil and D. Robson, Top-of-Line Corrosion Control in Large Diameter Wet Gas Pipelines, Int. Pet. Technol. Conf., Doha, Qatar, 2009, Paper IPTC-13733-MS. doi: 10.2523/IPTC-13733-MS

13. H. Li, K.M. Yap and S. Srinivasan, Evaluation of Top-of-Line Corrosion Model for Multiphase Oil and Gas Environments, NACE Corros. Conf., 2018, Paper 51318-11223.

14. S.L. Asher, W. Sun, R. Ojifinni, J. Pacheco, C. Li, J. Nelson and S. Ling, Top of the Line Corrosion Prediction in Wet Gas Pipelines, NACE Corros. Conf., 2012, Paper C-20120001303.

15. I.L. Rosenfeld and K.A. Zhigalova, Uskorennyye metody korrozionnykh ispytaniy metallov (teoriya i praktika) (Accelerated Methods of Corrosion Testing of Metals (Theory and Practice), Moscow: Metallurgiya, 1966, 347 pp. (in Russian). 
16. R.K. Vagapov, K.A. Ibatullin and D.N. Zapevalov, Corrosion Processes on Steel Under Conditions of Moisture Condensation and in the Presence of Carbon Dioxide, Chem. Pet. Eng., 2020, 56, no. 7-8, 673-680. doi: 10.1007/s10556-020-00825-5

17. Yu.I. Kuznetsov, N.N. Andreev, K.A. Ibatullin and S.V. Oleinik, Protection of lowcarbon steel from carbon dioxide corrosion with volatile inhibitors. I. Liquid phase, Prot. Met., 2002, 38, no. 4, 322-328. doi: 10.1023/A:1019601115782

18. Yu.I. Kuznetsov, N.N. Andreev, K.A. Ibatullin and S.V. Oleinik, Protection of lowcarbon steel from carbon dioxide corrosion with volatile inhibitors. II. Vapor phase, Prot. Met., 2003, 39, no. 1, 19-22.

19. Yu.I. Kuznetsov, N.N. Andreev and K.A. Ibatullin, On the adjustment of $\mathrm{pH}$ with lower amines in carbon dioxide corrosion of steels, Prot. Met., 1999, 35, no. 6, 532-536.

20. $\mathrm{CO}_{2}$ Corrosion Control in Oil and Gas Production, Published for EFC by The Institute of Materials. London, Eds.: M.V. Kermani and L.M. Smith, 1997, 53 pp.

21. J. Marsch, Materials Selection For Offshore Pipelines - a European Perspective, NACE Corros. Conf., 2012, Paper 51312-01649.

22. Y.H. Sun and S. Nešić, A parametric study and modeling on localized $\mathrm{CO}_{2}$ corrosion in horizontal wet gas flow, NACE Corros. Conf., 2004, Paper 380.

23. R.K. Vagapov, D.N. Zapevalov and K.A. Ibatullin, Study of corrosion of gas production infrastructure objects in the presence of $\mathrm{CO}_{2}$ by the methods of analytical control, Zavod. Lab., Diagn. Mater., 2020, 86, no. 10, 23-30. (in Russian). doi: 10.26896/1028-68612020-86-10-23-30

24. R. Nyborg and A. Dugstad, Top of Line Corrosion and Water Condensation Rates in Wet Gas Pipelines, NACE Corros. Conf., 2007, Paper 07555.

25. Y.M. Gunaltun and D. Larrey, Water-condensation rate critical in predicting, preventing TLC in wet-gas lines, Oil Gas J., 2000, 98, no. 28, 58-63.

26. D. Hinkson, M. Singer, S. Nešić, and Z. Zhang, A Study of the Chemical Composition and Corrosivity of the Condensate in Top of the Line Corrosion, NACE Corros. Conf., 2008. Paper 08466

27. X. Jiang, D. Qu, X. Song, X. Liu and Y. Zhang, Critical water content for corrosion of $\mathrm{X} 65$ mild steel in gaseous, liquid and supercritical $\mathrm{CO}_{2}$ stream, Int. J. Greenhouse Gas Control, 2019, 85, 11-22. doi: 10.1016/j.ijggc.2019.03.020

28. R.K. Vagapov, Resistance of steels under operating conditions of gas fields containing aggressive $\mathrm{CO}_{2}$ in the produced media, Materialovedenie (Material Science), 2021, no. 8, 41-47 (in Russian). doi: 10.31044/1684-579X-2021-0-8-41-47

29. Y. Chen, L. Zhang, H. Qin, L. Xu and M. Lu, Effects of Temperature on $\mathrm{CO}_{2}$ Top of Line Corrosion of Pipeline Steel, NACE Corros. Conf., 2011, Paper 51300-11327.

30. J.R. Piccardino, M. Stuvik, Y. Gunaltun and T. Pornthep, Internal Inspection of Wet Gas Lines Subject to Top of the Line Corrosion, NACE Corros. Conf., 2004, Paper 04354.

31. Y. Gunaltun, D. Larrey, S. Punpruk and S. Suryani, Design of Multiphase Offshore Gas Pipelines with High Risk of Sweet Top of the Lines Corrosion, NACE Corros. Conf., 2013, Paper 2290. 
32. U. Kaewpradap, M. Singer, S. Nešić and S. Punpruk, Top Of The Line Corrosion Comparison Of Model Predictions With Field Data, NACE Corros. Conf., 2012, Paper 1449.

33. R.K. Vagapov and D.N. Zapevalov, Corrosion Activity of Operating Conditions for the Steel Equipment and Pipelines in the Plants Extracting $\mathrm{CO}_{2}$-Containing Gases, Metallurgist, 2021, 65, 50-61. doi: 10.1007/s11015-021-01132-X

34. L.J. Mu and W.Z. Zhao, Investigation on carbon dioxide corrosion behaviour of HP13Cr110 stainless steel in simulated stratum water, Corros. Sci., 2010, 52, no. 1, 82 89. doi: $10.1016 /$ j.corsci.2009.08.056

35. D. Precoor, A Study Of Methanol Corrosion In Wet Sour Systems, With and Without Inhibition, NACE Northern Area Western Conference, 2010, Calgary (Alberta), 1-21.

36. A. Qasim, M.S. Khan, B. Lal and A.M. Shariff, A perspective on dual purpose gas hydrate and corrosion inhibitors for flow assurance, J. Pet. Sci. Eng., 2019, 183, Article 106418. doi: $\underline{10.1016 / j . p e t r o l .2019 .106418}$

37. R.K. Vagapov, The destruction of steel equipment and pipelines at gas fields due to corrosion processes in the presence of aggressive components, Tekhnol. Met. (Technology of Metals), 2021, no. 3, 47-54 (in Russian). doi: 10.31044/1684-24992021-0-3-47-54

38. B.F.M. Pots and E.L.J.A. Hendriksen, $\mathrm{CO}_{2}$ corrosion under scaling conditions - the special case of top-of-line corrosion in wet gas pipelines, NACE Corros. Conf., 2000, Paper 00031.

39. M. Singer, D. Hinkson, Z. Zhang, H. Wang, and S. Nešić, $\mathrm{CO}_{2}$ Top-of-the-Line Corrosion in Presence of Acetic Acid: A Parametric Study, Corrosion, 2013, 69, no. 7, 719-735. doi: $\underline{10.5006 / 0737}$

40. G. Svenningsen, R. Nyborg, L. Torri, T. Cheldi and P. Cavassi, Top of Line Corrosion Testing for a Gas Field with Acetic Acid and Low $\mathrm{CO}_{2}$, NACE Corros. Conf., 2016, Paper 51316-7275.

41. M. Singer, S. Nešić and Y.M. Gunaltun, Top of the Line Corrosion in Presence of Acetic Acid and Carbon Dioxide, NACE Corros. Conf., 2004, Paper 04437.

42. T.R. Andersen. A.M.K. Halvorsen, A. Valle, G.P. Kojen, and A. Dugstad, The influence of condensation rate and acetic acid concentration on TOL-corrosion in multiphase pipelines, NACE Corros. Conf., 2007. Paper 07312.

43. O.A. Nafday and S. Nešić, Iron carbonate film formation and $\mathrm{CO}_{2}$ corrosion in the presence of acetic acid, NACE Corros. Conf., 2005, Paper 05295.

44. Z. Jia, X. Li, C. Du, Z. Liu and J. Ga, Effect of acetic acid on $\mathrm{CO}_{2}$ corrosion of $3 \mathrm{Cr}$ lowalloy steel, Mater. Chem. Phys., 2012, 132, 258-263. doi: 10.1016/j.matchemphys.2011.08.034

45. P.C. Okafor and S. Nešić, Effect of acetic acid on $\mathrm{CO}_{2}$ corrosion of carbon steel in vaporwater two-phase horizontal flow, Chem. Eng. Commun., 2007, 194, no. 2, 141-157. doi: $\underline{10.1080 / 00986440600642975}$ 